\title{
The effect of temperature on railway rolling noise
}

\author{
G. Squicciarini, D.J. Thompson, M.G.R. Toward and R.A. Cottrell \\ Institute of Sound and Vibration Research, University of Southampton, \\ Highfield, Southampton, SO17 1BJ, UK
}

Corresponding author address:

Dr. Giacomo Squicciarini

Institute of Sound and Vibration Research

University of Southampton

Southampton SO17 1BJ

UK

e-mail: g.squicciarini@soton.ac.uk 


\begin{abstract}
The stiffness and damping of railpads in a railway track are affected by changes in environmental temperature. As a result, the rolling noise radiated by trains increases as the temperature increases. This paper quantifies this effect for a ballasted track equipped with natural rubber railpads and also studies the behaviour of a cork reinforced rubber railpad. By means of measurements in a temperature-controlled environment it is shown that the shear modulus of the natural rubber increases by a factor of 6 when the temperature is reduced from $40^{\circ} \mathrm{C}$ to $-20^{\circ} \mathrm{C}$. The loss factor increases from 0.15 at $40{ }^{\circ} \mathrm{C}$ to 0.65 at $-20^{\circ} \mathrm{C}$. The shear modulus of the cork reinforced rubber increases by a factor of 10 and the loss factor shows the typical trend of transition between rubbery and glassy regions. Railpad stiffness estimated from decay rates measurements at different temperatures is shown to follow to same trend. Field measurements of the noise from passing trains have been carried out for temperatures between $0{ }^{\circ} \mathrm{C}$ and $35^{\circ} \mathrm{C}$ showing an increase of about $3-4 \mathrm{~dB}$. Similar results are obtained from predictions of noise using the measured dependence of pad stiffness.
\end{abstract}

Author Keywords: rolling noise, railpad stiffness, temperature, railway noise, rubber 


\section{$1 \quad$ Introduction}

The most important noise generation mechanism for trains running along a straight track is rolling noise which is induced by the roughness of the wheel and rail surfaces. This roughness generates vibration of both elements which in turn radiates sound. Both the wheel and the track radiation are important, with the track normally being dominant below $2 \mathrm{kHz}^{1}$.

In a ballasted railway track, the rails are supported on sleepers, usually made of concrete, embedded in ballast. The rails are attached to the sleepers by a fastening system that contains an isolating mat (railpad) between them. The main functions of the pad are to distribute the load from the rail onto the sleeper surface and to isolate the sleepers and ballast from impact loading 2 . The rail clips, which hold the rail in place and

prevent rail roll, are much more flexible than the pads, typically by two orders of magnitude. The stiffness and damping of the railpads affect the noise radiated by the track, with a soft pad allowing the vibration to propagate further along the rail and hence to radiate more noise ${ }^{3}$. The attenuation of vibration along the rail is also known as the track decay rate. This is affected by the railpad stiffness, particularly for frequencies between about $250 \mathrm{~Hz}$ and $2 \mathrm{kHz}$.

Various materials are used for railpads including natural and synthetic rubbers. Due to their large Poisson ratio, rubbers have a high compressional stiffness so, to overcome this and allow softer railpads, forms are commonly used including studs, dimples or grooves or materials with embedded particles such as cork.

The dynamic properties of rubber are known to be strongly affected by temperature but the effect of this on noise is not usually taken into account. This paper studies the effects that temperature has on the stiffness and damping of railpads and consequently on the noise radiated during a train pass-by. In rolling noise models pad stiffness is usually a 
constant parameter for a defined pad type and potential changes due to temperature are treated as a source of uncertainty. Quantifying and taking into account the effect of environmental temperature on pad stiffness is a key improvement to develop more reliable models and can help in understanding seasonal and diurnal differences.

Various standard methods exist to measure the stiffness of railpads. To determine the stiffness related to track dynamic performance, quasi-static or low frequency dynamic large amplitude tests are carried out to determine the secant stiffness representative of the deflection under train loading ${ }^{4}$. For vibration at audio frequencies, small strain dynamic stiffnesses are more appropriate and can be measured by methods described in $^{5,6}$.

The dependence of railpad stiffness and damping on frequency and preload has been investigated in ${ }^{7-9}$ using the method from ${ }^{6}$. It has been shown that, for a given preload, the stiffness can increase by about $50 \%$ between $50 \mathrm{~Hz}$ and $1-2 \mathrm{kHz}$, while the loss factor does not vary much with either preload or frequency. The load dependence of the stiffness, however, is strongly determined by the shape of the railpad as well as the material. Similar findings have been presented in ${ }^{10}$ by applying a direct $\operatorname{method}^{5}$ on three different rubber specimens representative of railpads.

The dynamic behaviour of rubbers is also known to depend strongly on temperature. In particular, at low temperatures rubber becomes stiffer while at high temperatures it becomes softer. These two extremes are known as the glassy region and the rubbery region ${ }^{11,12}$. The region between them is known as the transition region in which the stiffness increases rapidly with decreasing temperature. The damping loss factor reaches its highest values in this transition region. These phenomena are well known and their effects have been widely investigated in many applications for passive noise control ${ }^{12,13}$, including rail dampers ${ }^{14}$. Nevertheless, little is known about the temperature dependence of railpads and the consequent effect on the decay rate of the 
rail and the sound radiated by the track. For natural rubber (NR), as used in one of the railpads assessed in this study, the transition from rubbery to glassy regions is expected to take place in between -70 and $30{ }^{\circ} \mathrm{C}$. Within the transition, the stiffness can increase considerably and this can potentially lead to a significant effect on the track decay rate. The pass-by noise is therefore expected to be lower at low temperatures and higher at high temperatures.

This paper presents an extension of the research introduced by Broadbent et al. ${ }^{15}$. The stiffness and loss factor of railpad materials is first characterised as a function of temperature and frequency. The main argument assessed is whether normal changes in temperature can affect railpad stiffness, and thus decay rate, to such an extent that pass-by noise is also modified by a significant amount and whether this can be modelled through changes in the track decay rates or even through the knowledge of the temperature-dependent pad properties.

Section 2 describes the measurements on the material stiffness and loss factor of two railpads in a temperature-controlled environment. Section 3 reports measurements of decay rates executed on a test track for a wide range of railpad temperatures for one of these pads and Section 4 assesses the effect on noise by comparing predictions with field measurements.

\section{Dynamic stiffness measurement in a temperature-controlled environment}

\section{$2.1 \quad$ Railpads}

Two types of railpads are considered in this study. The first one was a natural rubber studded pad (dimensions $180 \mathrm{~mm} \times 150 \mathrm{~mm}$, excluding locating tabs) while the second was flat and made of cork reinforced rubber (dimensions $190 \mathrm{~mm} \times 140 \mathrm{~mm}$ ). Both railpads have an overall thickness of $10 \mathrm{~mm}$. Nominally, the natural rubber pad has low 
stiffness (20-25 MN/m, static $\left.{ }^{7}\right)$ while the cork rubber has medium stiffness $(65 \mathrm{MN} / \mathrm{m}$, static $\left.^{16}\right)$. However, it is an objective of this paper to show detailed measurement of dynamic properties for both.

The same natural rubber pads addressed here have also been previously studied in ${ }^{7}$ $\operatorname{and}^{9}$, although without any specific emphasis on temperature dependence.

\section{$2.2 \quad$ Test set-up}

A series of experiments has been carried out to determine the effect of temperature on the stiffness of the two railpad materials ${ }^{15}$. For this, a test rig described in ${ }^{17}$ (see Figure 1) has been used to measure the shear stiffness of small samples of the material.

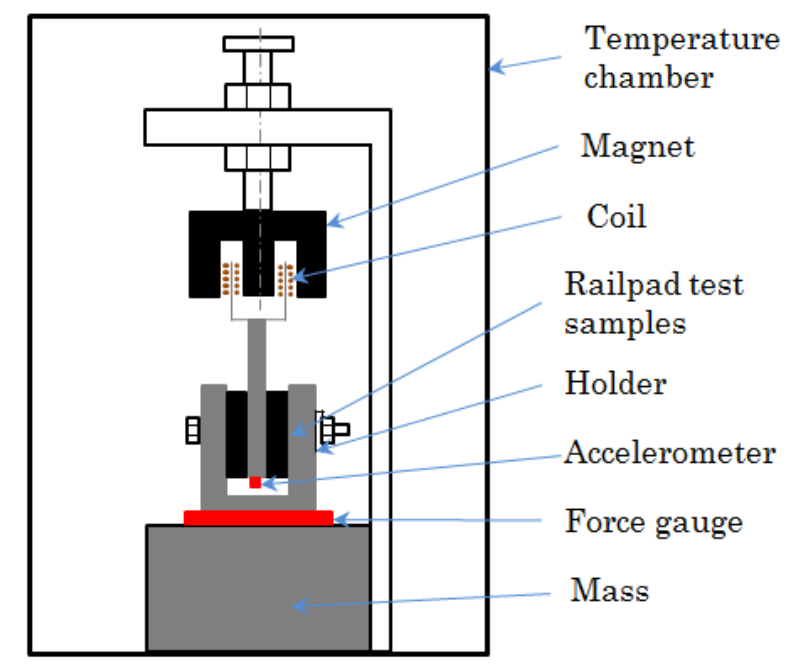

Figure 1. Experimental set up used for the laboratory experiments to determine the railpad shear modulus and damping loss factor at different temperatures.

Four separate samples (approximately $20 \times 15 \times 5 \mathrm{~mm}$ ) of each material were cut from the corners of the railpad. They were mounted in a sample holder (two on each side), and were excited in shear along their largest face by a small coil and magnet exciter. The base of the holder was attached to a seismic mass of $31 \mathrm{~kg}$ to provide a "blocked" termination. A force transducer was used to measure the force transmitted to the seismic mass while the input vibration on the source side was measured using an 
accelerometer. The transfer function between force and acceleration was measured by a Data Physics Quattro analyser using a random excitation applied to the shaker.

These measurements were carried out with the test rig installed inside a temperaturecontrolled chamber and tests were carried out at different temperatures across the range $-20^{\circ} \mathrm{C}$ to $40^{\circ} \mathrm{C}$ with steps of $5{ }^{\circ} \mathrm{C}$. A thermocouple located close to the samples was used to record the temperature during the measurements. From initial experiments a period of 15 minutes at constant temperature $\left( \pm 0.5^{\circ} \mathrm{C}\right.$ of the desired temperature) was found to be sufficient to allow the sample material to reach the required temperature.

\subsection{Results}

The transfer function, $H$, between the input acceleration, $a$, and the transmitted force, $F$, can be converted to the dynamic shear (complex) stiffness by

$$
K_{d}=-\frac{\omega^{2}}{n_{s}} H=-\frac{\omega^{2}}{n_{s}} \frac{F}{a}
$$

where $\omega$ is the angular frequency and $n_{s}$ is the number of samples held in the test rig during the measurements ( 4 in this case). The shear modulus can then be derived from the geometry of the tested samples as

$$
G=\frac{K_{d} h}{A}=G^{\prime}+i G^{\prime \prime}
$$

with $h$ being the height and $A$ the area of each sample under test. The real and imaginary part of the complex shear modulus are also referred to as the storage modulus $\left(G^{\prime}\right)$ and loss modulus $\left(G^{\prime \prime}\right)$. In this case $h=0.005 \mathrm{~m}$ and $A=3 \times 10^{-4} \mathrm{~m}^{2}$. The loss factor is obtained from

$$
\eta=\frac{\operatorname{Im}\left(K_{d}\right)}{\operatorname{Re}\left(K_{d}\right)}
$$

Figure 2 shows the measured shear modulus and loss factor of the natural rubber material. One-third octave band resolution is adopted for clarity as it allows sufficient 
accuracy for an acoustic assessment of the railway track. The shear modulus increases slightly with frequency and decreases with increasing temperature. The frequency dependence is more pronounced at low temperatures, whereas the shear modulus tends to be fairly constant with frequency at higher temperatures. The loss factor (Figure 2(b)) is relatively low at high temperatures, increasing at lower temperatures. The loss factor shows a less clear trend with frequency but to a first approximation it can be assumed to be constant over the frequency range of the measurements. From the coherence of these measurements, the transfer function measurements were valid over the whole range $200-2500 \mathrm{~Hz}$.

Figure 3 shows the shear modulus and loss factor obtained for the cork reinforced rubber. In this case the coherence was found to drop at low and high frequency, so results are displayed only for the frequency range where the coherence is greater than 0.8. The results from the rig are less reliable at low frequencies for high stiffnesses and at high frequencies for low stiffnesses. However, from these results the complete transition from rubbery to glassy region can be recognised. The shear modulus in fact stops increasing at $-15{ }^{\circ} \mathrm{C}$, possibly showing the beginning of the plateau typical of the glassy region. The loss factor increases as the temperature decreases to about $0{ }^{\circ} \mathrm{C}$; here it reaches a maximum, decreasing again for lower temperatures. This is typical of the behaviour of the loss factor in the transition region ${ }^{11}$.

The dependence of the shear modulus on both frequency and temperature is explained in more detail in the sections below. 


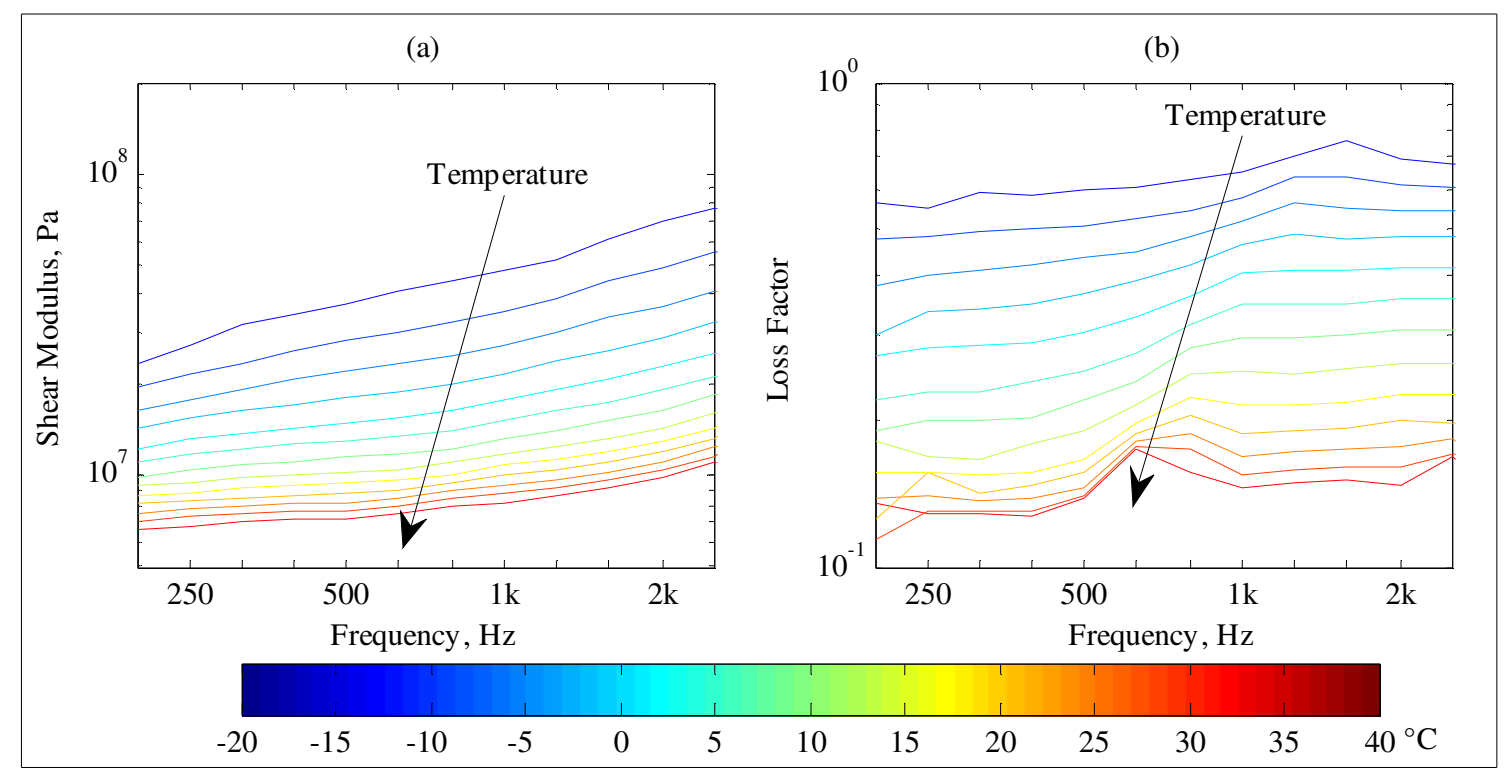

Figure 2. (a) Shear modulus magnitude and (b) loss factor of natural rubber railpad materials over range of frequencies at different temperatures. Temperature ranges from $-20^{\circ} \mathrm{C}$ to $40{ }^{\circ} \mathrm{C}$ with a step of $5{ }^{\circ} \mathrm{C}$. One-third octave band resolution.

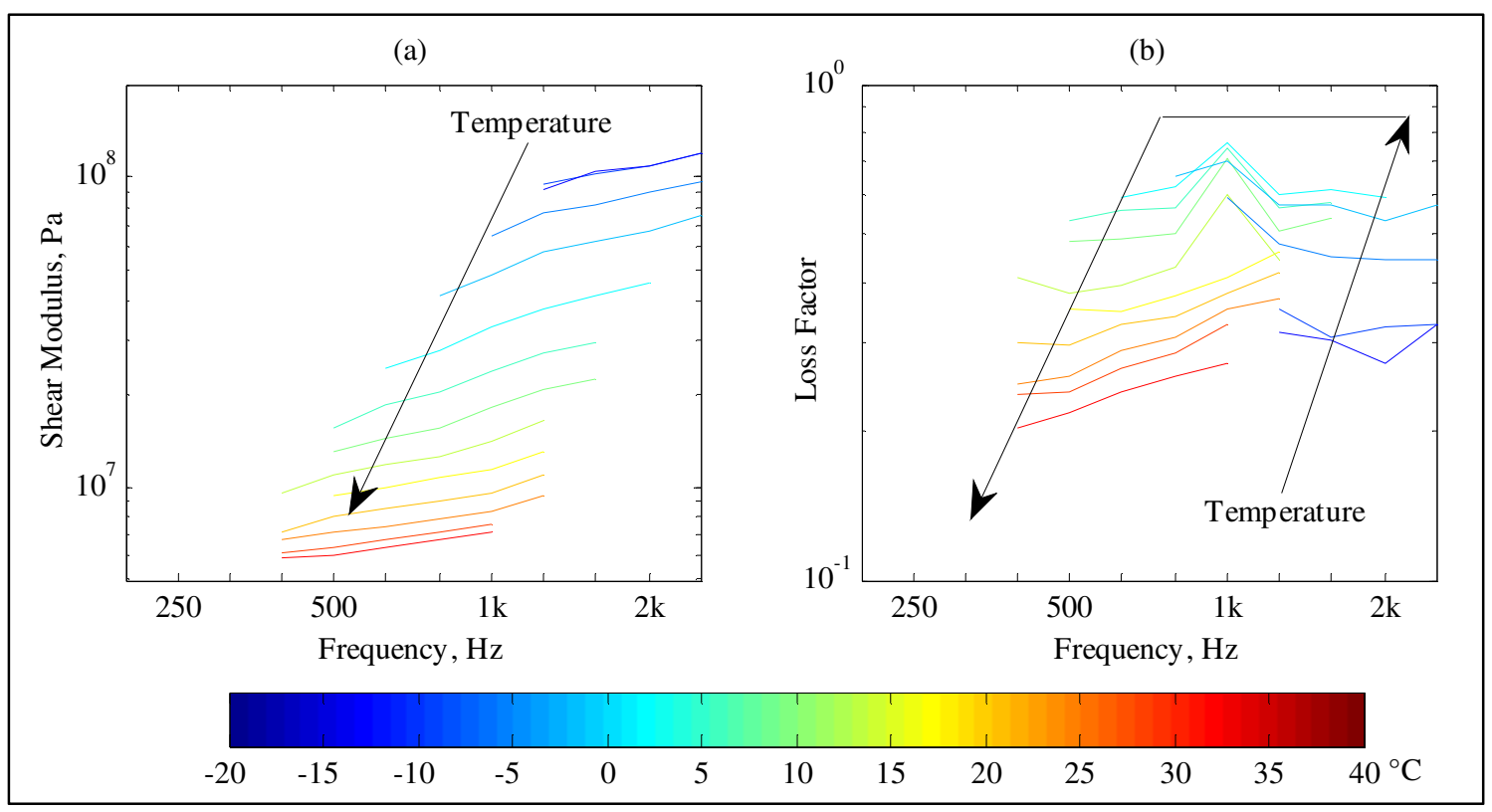

Figure 3. (a) Shear modulus magnitude and (b) loss factor of cork rubber railpad materials over range of frequencies at different temperatures. Temperature ranges from $-20^{\circ} \mathrm{C}$ to $40{ }^{\circ} \mathrm{C}$ with a step of $5{ }^{\circ} \mathrm{C}$. One-third octave band resolution. 


\section{$2.4 \quad$ Temperature dependence}

From each measurement, results at $1 \mathrm{kHz}$ have been used to determine the temperature dependence. This is obtained from the shear modulus and loss factor values corresponding to the frequency band centred at $1 \mathrm{kHz}$. When the result in this band is not available due to poor coherence the band at $1.25 \mathrm{kHz}$ has been used instead. The results are shown in Figure 4. For natural rubber the shear modulus increases by almost a factor of 6 in the temperature range analysed, while the loss factor drops from 0.65 at $-20^{\circ} \mathrm{C}$ to 0.15 at $40{ }^{\circ} \mathrm{C}$. The trend found for the cork reinforced material confirms that transition to the glassy region occurs in the range measured. This material is more sensitive to temperature, with the shear modulus increasing by a factor of 13 in the range analysed. The loss factor is higher than that for natural rubber over most of the temperature range and reaches a maximum value of 0.8 at $0{ }^{\circ} \mathrm{C}$.

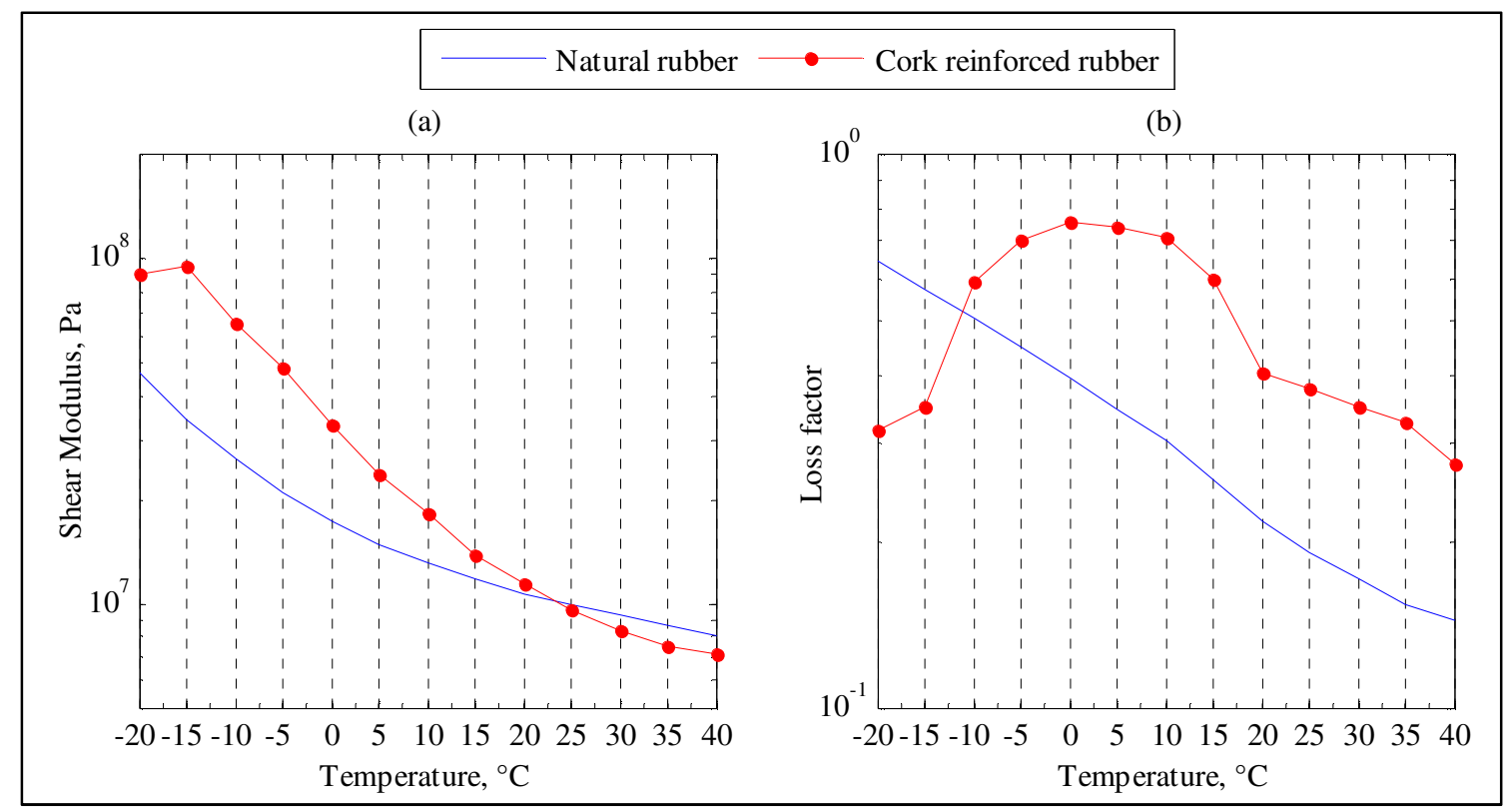

Figure 4. Shear modulus (a) and loss factor (b) measured at different temperature. Results are obtained from $1 \mathrm{kHz}$ frequency band.

\section{$2.5 \quad$ Frequency dependence}

The frequency dependence of the shear modulus has already been shown in Figures 2 and 3. It is known that, for a general elastomer, the slope of the shear storage modulus 
with log frequency is proportional to the loss modulus ${ }^{14,18}$. Consequently, the dependence of the shear storage modulus $\left(G^{\prime}\right)$ on frequency at any temperature $T$ can be expressed as:

$G^{\prime}(f, T)=\left(\frac{f}{f_{\text {ref }}}\right)^{2 \eta\left(f_{\text {ref }}, T\right) / \pi} G^{\prime}\left(f_{\text {ref }}, T\right)$

where the reference quantities, subscript ref, are calculated from the band centred at 1 $\mathrm{kHz}$. Assuming a constant loss factor, it is possible to approximate the frequencydependent behaviour of the shear modulus. This allows a simple equation to be used in noise predictions models, instead of the measured data, to include the effect of frequency-dependent stiffness. In addition, eq. (4) allows the frequency range to be extended beyond what was measured, especially where the measurements are affected by the test rig capabilities. Figure 5 shows the trend given by eq. (4) compared with measured results of Figure 2(a) and Figure 3(a). The agreement is satisfactory and suggests that eq. (4) can be used reliably to account for frequency and temperature dependent stiffness if the loss factor, assumed constant with frequency, is known at each temperature.

It is important to note that the force amplitude in these measurements is very small and the resulting response is in the small-strain region. Strain values have been estimated to be below $10^{-5}$ and the rms value of the force is, in all the tests, less than $0.1 \mathrm{~N}$. For this reason the shear modulus can be considered to be independent from the amplitude of the excitation ${ }^{19}$. 
(a)

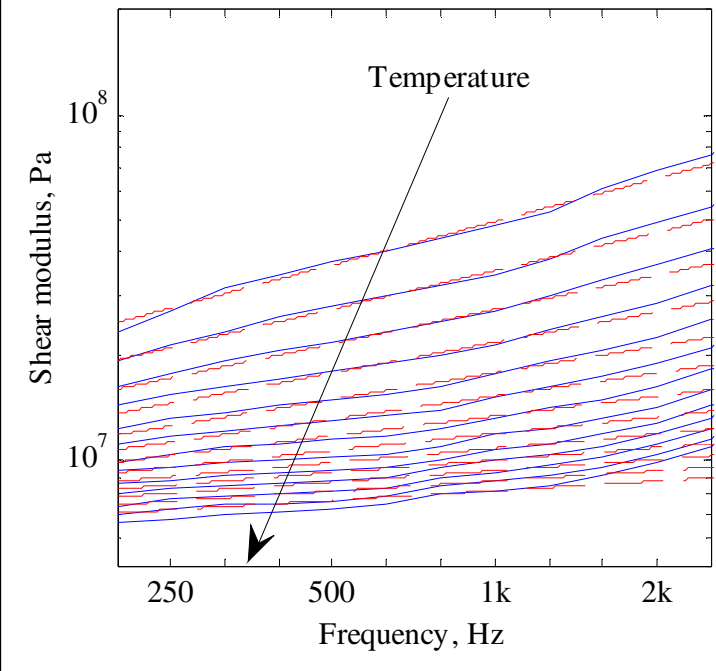

(b)

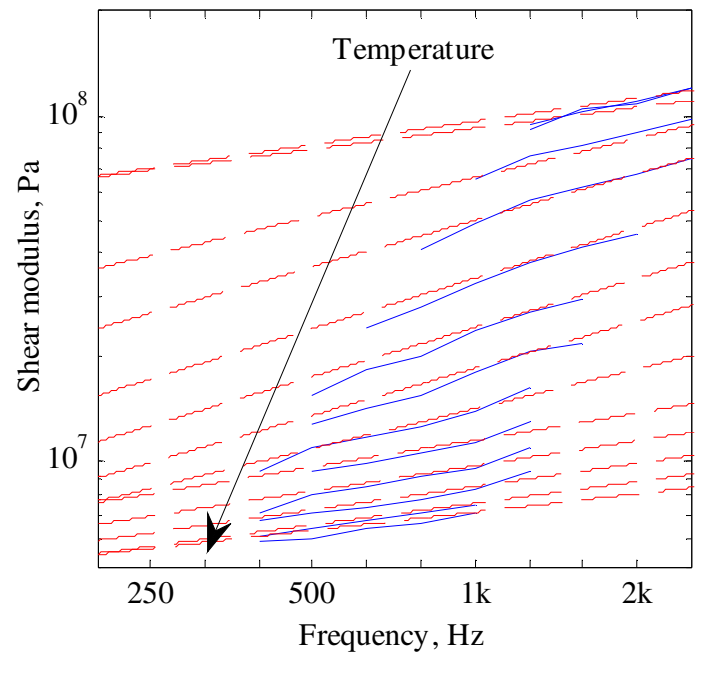

Figure 5. Magnitude of shear modulus from measurements (-) and prediction (------) according to eq. (4). Temperature ranges from $-20^{\circ} \mathrm{C}$ to $40{ }^{\circ} \mathrm{C}$ with a step of $5{ }^{\circ} \mathrm{C}$. (a) natural rubber (b) cork reinforced rubber.

\section{$3 \quad$ Field measurements of decay rates and pad stiffness}

\subsection{Measurements of decay rates}

To find the effect of temperature on track properties, track decay rates (TDR) were measured on the University of Southampton test track for a wide range of temperatures. This test track was designed to be broadly representative of modern circulated track within the UK. It has a length of $32 \mathrm{~m}$ and is fitted with UIC 60 rail, 51 concrete monobloc sleepers with a mean spacing of $0.63 \mathrm{~m}$ (standard deviation $0.03 \mathrm{~m}$ ), $10 \mathrm{~mm}$ studded natural rubber pads with an effective vertical stiffness of approximately 120 $\mathrm{MN} / \mathrm{m}$ and compacted granite ballast to a depth of $0.3 \mathrm{~m}$ below the sleepers. The railpads correspond exactly to the natural rubber material measured above. The temperature was measured using a thermocouple inserted between railpad and sleeper. This temperature is compared with rail temperature and air temperature in Figure 6 for one of the days of measurement. Temperature at the sleeper/pad follows the air 
temperature for the first hours of the day but it is also influenced by the presence of the rail above which heats more with direct sunlight.

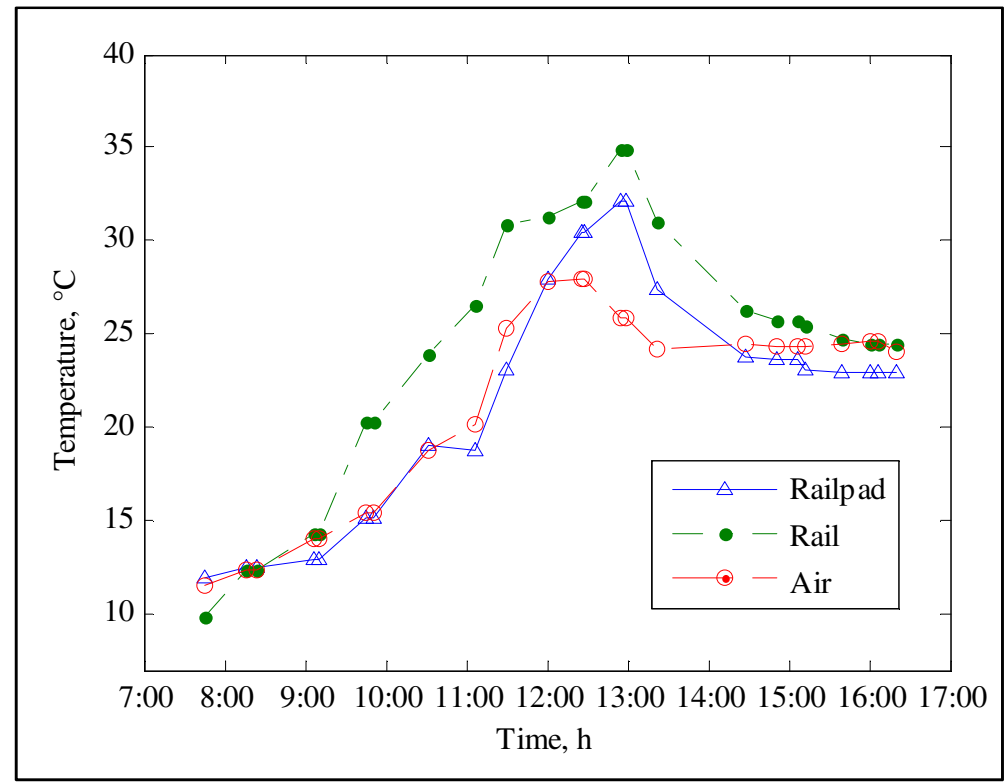

Figure 6. Example of temperature measured on the track and in the air in September 2012.

The standard measurement procedure for track decay rates described in EN15461 20 has been followed. This implies measuring the transfer functions $A$ (mobilities have been used in the present work) between a reference point $x_{0}$ and several points along the rail $x_{n}$. The decay rate can then be derived as

$$
D R=\frac{4.343}{\sum_{n=0}^{n_{\max }} \frac{\left|A\left(x_{n}\right)\right|^{2}}{\left|A\left(x_{0}\right)\right|^{2}} \Delta x_{n}}
$$

where $\Delta x_{n}$ is the length of rail associated with position $x_{n}$. Although the standard specifies the measurement grid, both in terms of spacing and length, the test track available (32 m long) limits the length of the grid. A measurement grid was marked up from a reference point 10 sleeper spans $(5.96 \mathrm{~m})$ from the rail end. Measurements were made at $1 / 4$-sleeper intervals from this point up to the 16 th sleeper span from the end, then at mid-span positions $17,18,20,22,26,30,34,38,42$ and 46. The total length covered by the grid is $23 \mathrm{~m}$ and this sets the minimum measurable decay rate at about 
$0.5 \mathrm{~dB} / \mathrm{m}$. The finite length of the test track also results in resonances clearly visible in the measured transfer function. However, averaging over one-third octave frequency bands smoothens this effect allowing the correct dynamic behaviour of the track to be captured.

Figure 7 shows the vertical TDR measured on a number of days covering temperatures between $-1{ }^{\circ} \mathrm{C}$ and $+30{ }^{\circ} \mathrm{C}$; the temperature reported is the average of the start and finish of the measurement. Clearly there is an increase of TDR with decreasing temperature and the large amount of variation recorded is likely to affect the radiated noise by a significant amount. It may be noted that the greatest variation with temperature occurs below $20^{\circ} \mathrm{C}$.

The lateral TDR is shown in Figure 8. In these results the temperature dependence is less pronounced and is clearly visible only below $10^{\circ} \mathrm{C}$.

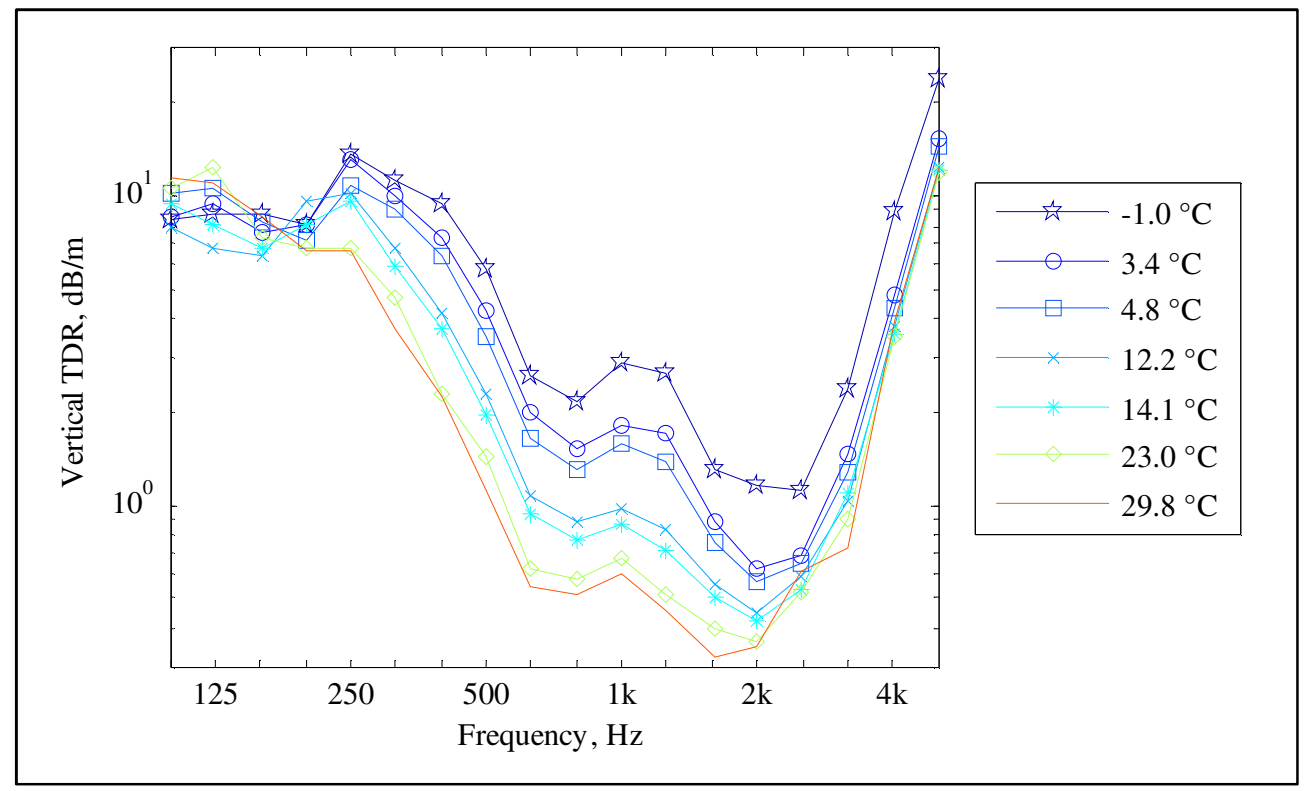

Figure 7. Vertical TDR measured for natural rubber pad at different temperatures. 


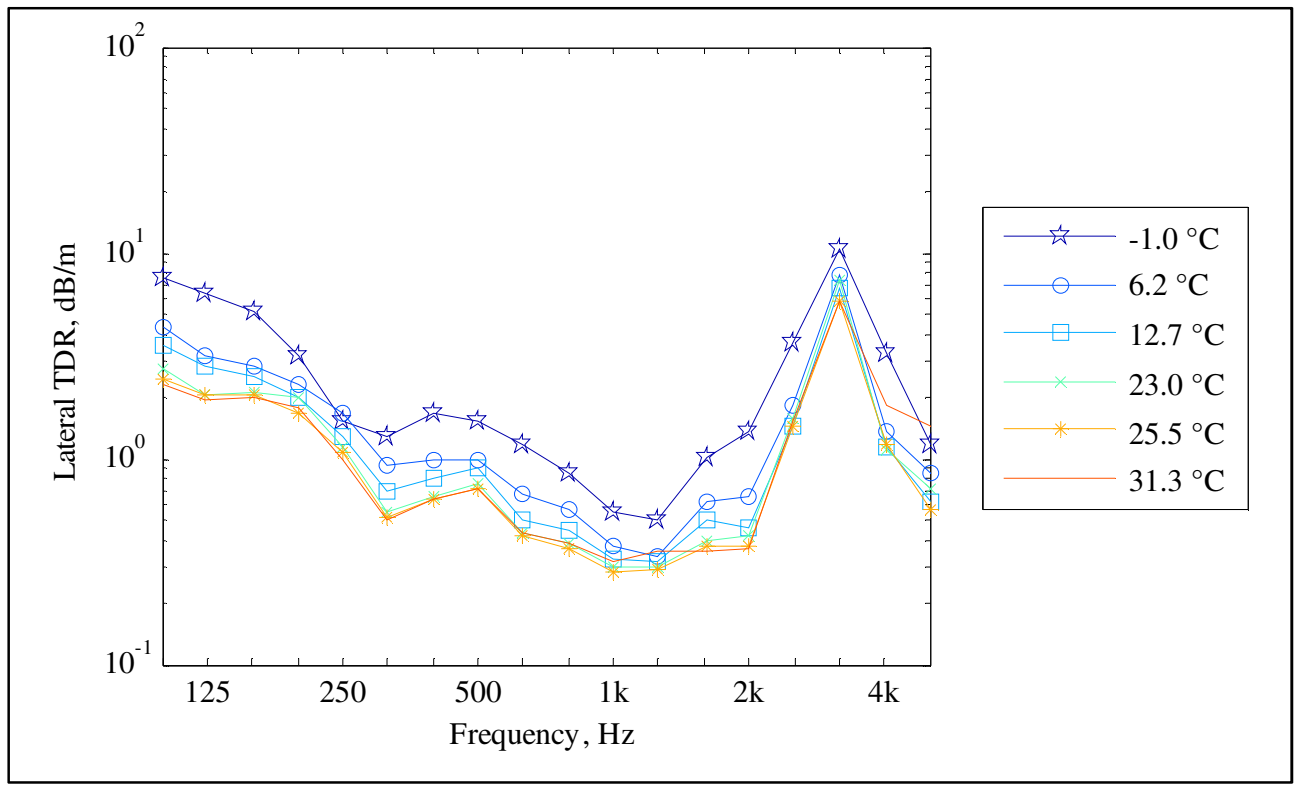

Figure 8. Lateral TDR measured for natural rubber pad at different temperatures.

\subsection{Model for track decay rate}

The equivalent pad stiffness was obtained by fitting analytical models of track vibration to the measured TDR data. This analytical model solves the wave propagation problem illustrated in Figure 9; it consists of an infinite Timoshenko beam supported by a twolayer foundation. The sleepers have been modelled as both flexible and rigid bodies ${ }^{1}$, resulting in only small differences in the estimated pad stiffness.

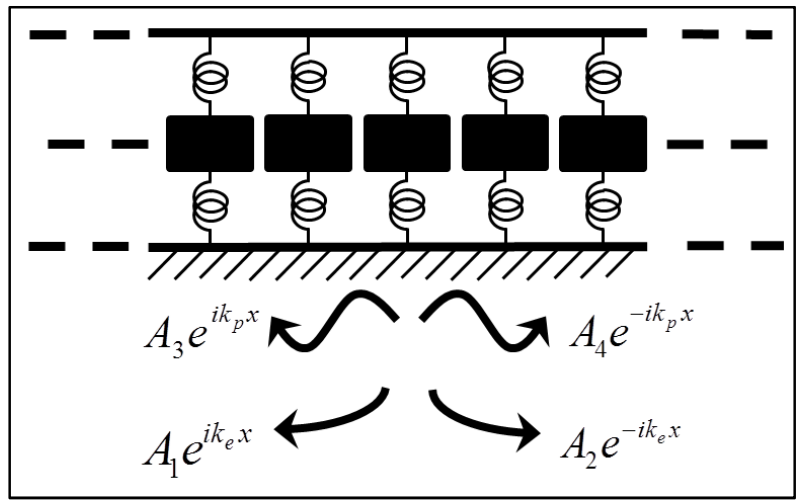

Figure 9. Schematic representation of waves travelling in an infinite beam on a two-layers foundation. (a): rigid sleeper.

The equation of motion of a Timoshenko beam accounting for the elastic foundation is ${ }^{1}$ : 
$G A \kappa \frac{\partial}{\partial x}\left(\phi-\frac{\partial u}{\partial x}\right)+s u+\rho A \frac{\partial^{2} u}{\partial t^{2}}=0$

where $s$ is a frequency-dependent support stiffness per unit length given by:

$$
s(\omega)=\frac{s_{p}(\omega)\left(s_{b}-\omega^{2} m_{s}\right)}{s_{p}(\omega)+s_{b}-\omega^{2} m_{s}}
$$

in which $s_{p}$ and $s_{b}$ are the pad and ballast dynamic stiffnesses per unit length for one rail, respectively, and $m_{s}$ is the sleeper mass per unit length of the rail. The ballast stiffness is assumed to be constant and is made complex with loss factor $\eta_{b}$. Conversely, the pad stiffness is made frequency-dependent according to eq. (2) with the loss factor $\eta_{p}$ taken from the laboratory measurement, see Figure 4(b), thus also including the effect of temperature.

If the sleeper is considered as a flexible body the equivalent stiffness of eq. (3) is calculated from the combination of the sleeper and pad dynamic where the latter includes the effect of ballast stiffness. This term is calculated by solving the equation of motion of a Timoshenko beam of finite length (representing the sleeper) over a stiffness layer representing the ballast ${ }^{1}$. In this case the ballast stiffness is taken as frequency dependent.

In either case (rigid or flexible sleeper) the characteristic equation of the rail is:

$$
k^{4}+\left(\frac{s-\rho A \omega^{2}}{G A \kappa}-\frac{\rho I \omega^{2}}{E I}\right) k^{2}+\frac{s-\rho A \omega^{2}}{E I}\left(1-\frac{\rho I \omega^{2}}{G A \kappa}\right)=0
$$

from which the wavenumbers of propagating and evanescent waves $k_{p}$ and $k_{e}$ can be obtained and decay rates computed from the imaginary part of the propagating wave as ${ }^{1}$ : 
Alternatively, a full solution of the forced problem can give the transfer mobilities along the rail and the procedure of the standard EN15461 ${ }^{20}$ can be applied to obtain the TDR. The two methods give similar results and the first one is adopted for this study.

Decay rates for vertical vibration calculated with the model with rigid sleepers are shown in Figure 10(a) for a range of pad stiffness values. The main parameters are listed in Table 1. Note that the railpad loss factor is kept constant in this example and also the pad stiffness is constant with frequency; the effect of having a frequencydependent stiffness is discussed below. The increase of the decay rate with pad stiffness is clearly highlighted in this figure. Examples of the TDR obtained with the flexible sleeper model for different values of pad stiffness are shown in Figure 10(b). The fluctuations characterising the results for pad stiffness above $200 \mathrm{MN} / \mathrm{m}$ are due to the bending modes of the sleeper; they would be less pronounced in a one-third octave band representation.

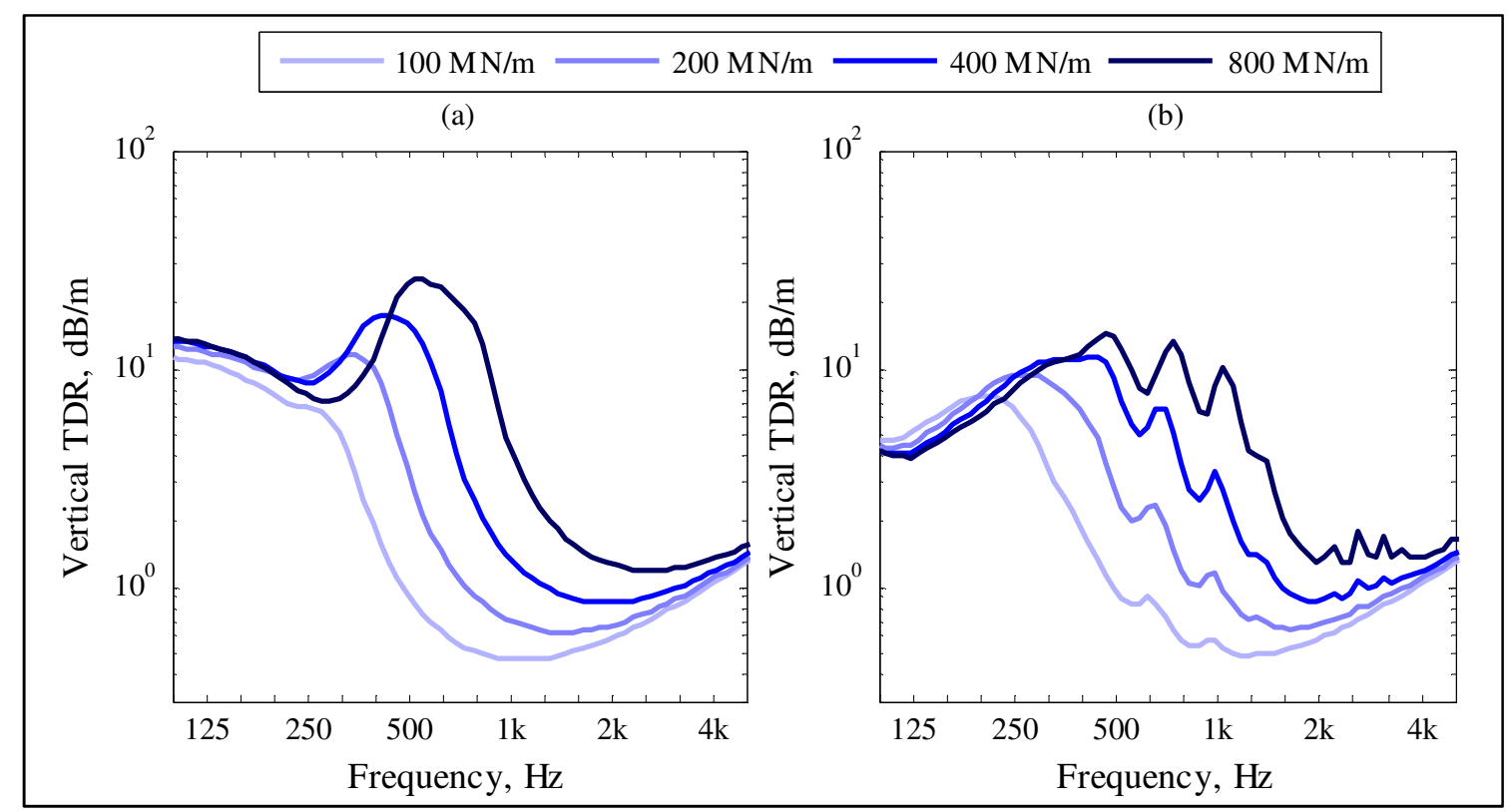

Figure 10. Examples of analytical calculations of TDR for Timoshenko beam on double elastic foundation with (a) rigid sleepers and (b) flexible sleepers. 
Table 1. Parameters used for analytical calculation.

\begin{tabular}{ll}
\hline Rail parameters & \\
\hline Vertical bending stiffness $\left(\mathrm{Nm}^{2}\right)$ & $6.42 \times 10^{6}$ \\
Density $\left(\mathrm{kg} / \mathrm{m}^{3}\right)$ & 7850 \\
Rail mass per length $(\mathrm{kg} / \mathrm{m})$ & 60 \\
Shear coefficient & 0.4 \\
Loss factor & 0.02 \\
\hline Pad parameters & {$[100200400$ 800] } \\
\hline Pad vertical stiffness $(\mathrm{MN} / \mathrm{m})$ & \\
Pad vertical and lateral loss factor & 0.2 \\
\hline Sleeper parameters & 280 \\
\hline Sleeper mass $(\mathrm{kg})$ & 41.3 \\
Sleeper Young's modulus $(\mathrm{GPa})$ & $5.45 \times 10^{6}$ \\
Bending stiffness $\left(\mathrm{Nm}{ }^{2}\right)$ & 0.15 \\
Sleeper Poisson's ratio & 0.83 \\
Sleeper shear coefficient & 2750 \\
Sleeper density $\left(\mathrm{kg} / \mathrm{m}^{3}\right)$ & 0.02 \\
Sleeper loss factor & 2.6 \\
Sleeper length $(\mathrm{m})$ & 0.6 \\
Sleeper spacing $(\mathrm{m})$ & \\
\hline Ballast parameters & $100(\mathrm{at} 100 \mathrm{~Hz})$ \\
\hline Vertical stiffness $(\mathrm{MN} / \mathrm{m})$ & $1450(\mathrm{at} 1 \mathrm{kHz})$ \\
(Frequency dependent) & 0.9 \\
Vertical loss factor & 35 \\
Lateral stiffness $(\mathrm{MN} / \mathrm{m})$ & 2.0 \\
Lateral loss factor & \\
\hline
\end{tabular}

Figure 11 shows the effect of a frequency-dependent pad stiffness where the dependence on frequency has been chosen according to eq. (4). In this case the reference frequency is $1 \mathrm{kHz}$ and the loss factor is assumed constant and equal to 0.2 . The effect is almost negligible for stiff railpads but is more evident for soft pads where the decay rates drop at a lower frequency. As a consequence, if the pad stiffness is estimated from curve fitting for a given measurement curve, as shown below, it is important to allow for the frequency dependence. For example, the model with frequency-dependent pad stiffness based on $200 \mathrm{MN} / \mathrm{m}$ at $1 \mathrm{kHz}$ would give similar results to a constant stiffness model of $180 \mathrm{MN} / \mathrm{m}$. As the results presented from the test rig in Section 2.4 are presented for 1 $\mathrm{kHz}$ it is more accurate to include the frequency dependency in the analytical model still 
showing results at the reference frequency for a proper comparison with the laboratory measurements.

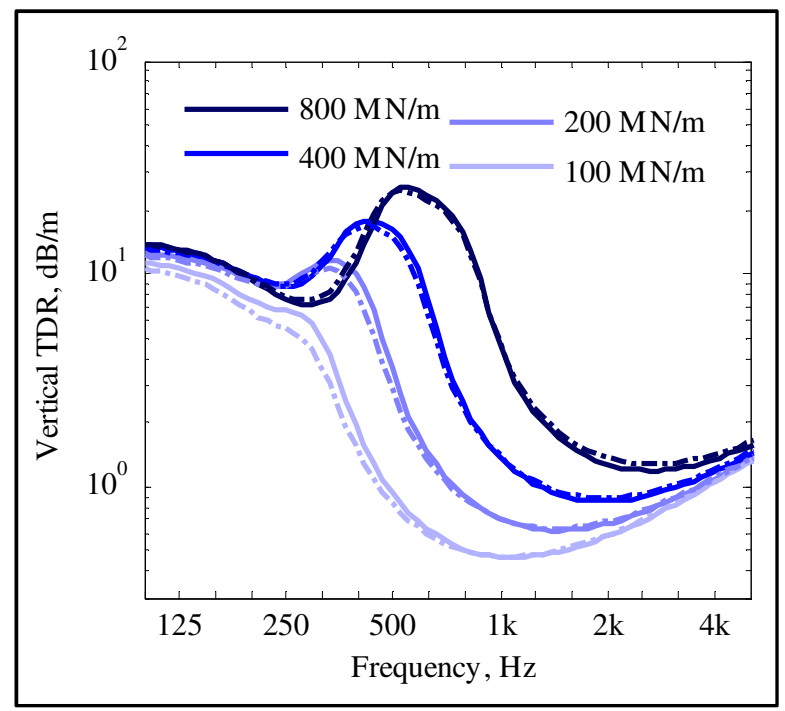

Figure 11. Track decay rate for rigid sleeper. ——: constant pad stiffness; —- - pad stiffness variable with frequency according to eq. (4), reference frequency is $1 \mathrm{kHz}$ and loss factor is assumed constant and equal to 0.2 .

\subsection{Estimates of railpad stiffness}

The railpad stiffness is estimated from the measured TDR results by curve fitting with predicted results. Within the curve fitting algorithm, the railpad stiffness $\left(s_{p}\right)$ is given an initial value of $100 \mathrm{MN} / \mathrm{m}$. A nonlinear least squares curve fitting problem is solved having the form of:

$$
\min _{\left(s_{p}\right)}\left\|f\left(s_{p}\right)\right\|_{2}^{2}=\min _{\left(s_{p}\right)}\left(\sum_{i=1}^{n} f_{i}\left(s_{p}\right)^{2}\right)
$$

where the objective function $f$ represents the difference between measured and calculated decay rates in each one-third octave frequency band $i$.

From Figures 10 and 12 it is clear that the effect of pad stiffness on decay rate is strongest at frequencies between about $200 \mathrm{~Hz}$ and $2 \mathrm{kHz}$. At low frequencies the decay rate is high and independent of pad stiffness. It drops to a much lower level at a 
frequency that depends on the pad stiffness; this corresponds to the onset of travelling waves in the rail. This can be at about $250 \mathrm{~Hz}$ for soft pads (100 MN/m) and up to around $800 \mathrm{~Hz}$ for stiff pads $(800 \mathrm{MN} / \mathrm{m})$. At higher frequencies other track properties not included in the model - such as the pinned-pinned resonance at about $1 \mathrm{kHz}$ and the presence of higher order waves - determine the main trend of the measured decay rates. For this reason the curve fitting procedure is performed only for the frequency bands centred between $200 \mathrm{~Hz}$ and $1 \mathrm{kHz}$.

Examples of fitted TDR for the vertical direction are compared with the corresponding measurement in Figure 12. The analytical model behind the fitted curves is the one with rigid sleepers although a similar result was found including flexible sleepers (results not reported here). The agreement between measurement and fitted curves is very good showing the capability of the model to give a good representation of the propagation of track vibration over distance in this frequency range.

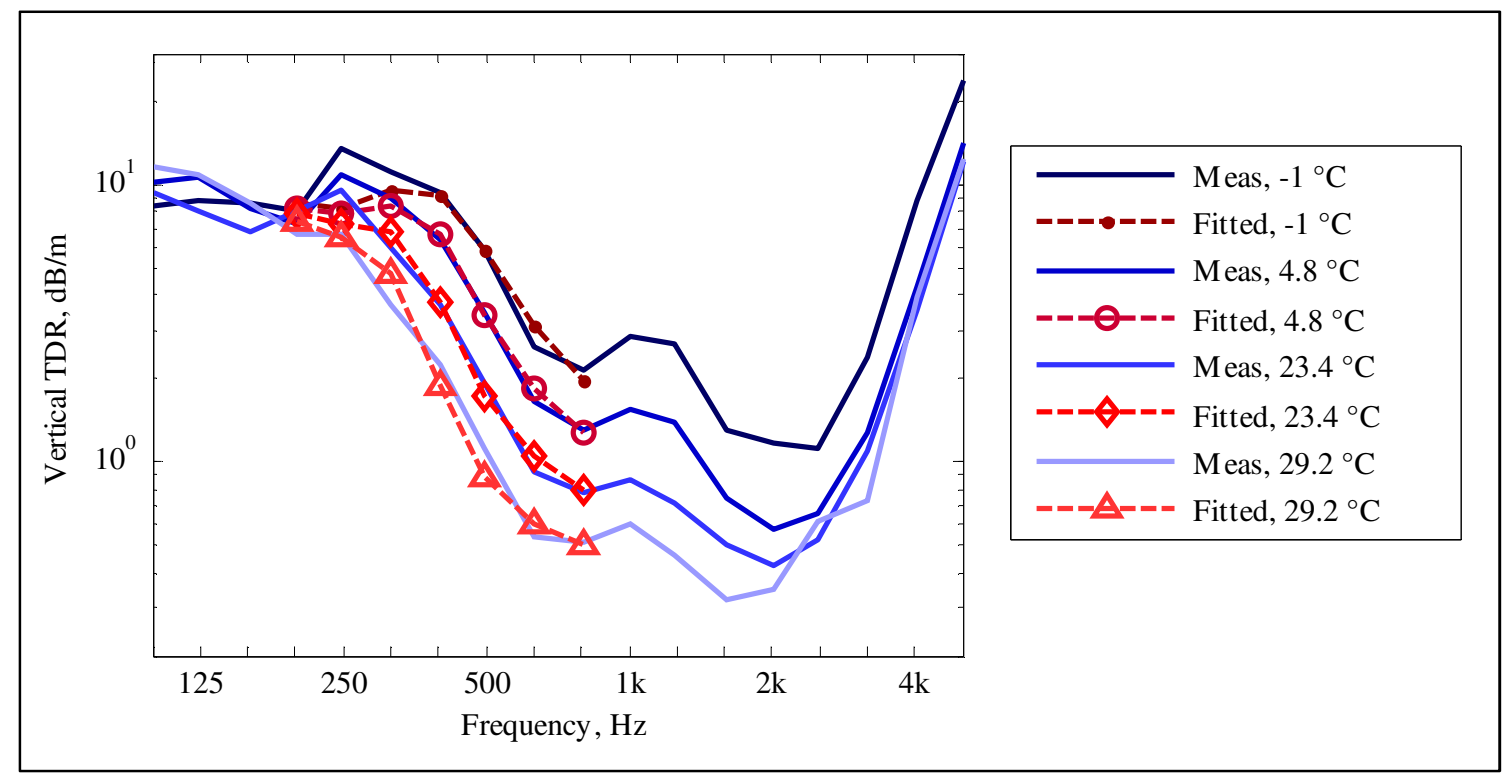

Figure 12. Examples of fitted and measured TDR for different temperatures, one-third octave band resolution.

The pad stiffness estimated from curve fitting the decay rates at all the temperatures available is presented in Figure 13; in this case also results from the lateral direction 
are shown. These have also been obtained by fitting decay rate measurements with a Timoshenko beam model over a double elastic foundation. The main limitation of using this approach for the lateral direction is that the effect of torsion is ignored. The values for lateral stiffness given by the best fitting approach are only representative of an overall stiffness in the lateral direction. The absolute value is not a correct representation of the lateral stiffness of the railpad itself but of the value to be used in this model to obtain the right decay rates. The trend of pad stiffness as a function of temperature estimated from the laboratory tests is also presented. For a given railpad geometry, the stiffness of the railpad is proportional to the shear modulus and the temperature dependence of the pad stiffness can be determined from that of the shear modulus. The stiffness is therefore obtained by multiplying the shear modulus (Figure 4(a)) by a constant factor at all temperatures. The constant factor has been chosen to give a value of $120 \mathrm{MN} / \mathrm{m}$ at $20{ }^{\circ} \mathrm{C}$ for the vertical stiffness and $18 \mathrm{MN} / \mathrm{m}$ for the lateral one. There is a good agreement between the results estimated from the laboratory tests and the pad stiffness estimated from curve fitting the decay rates at different temperatures in both directions. In interpreting the laboratory results a constant factor between vertical and lateral stiffness has been assumed which corresponds approximately to 7.5 . 


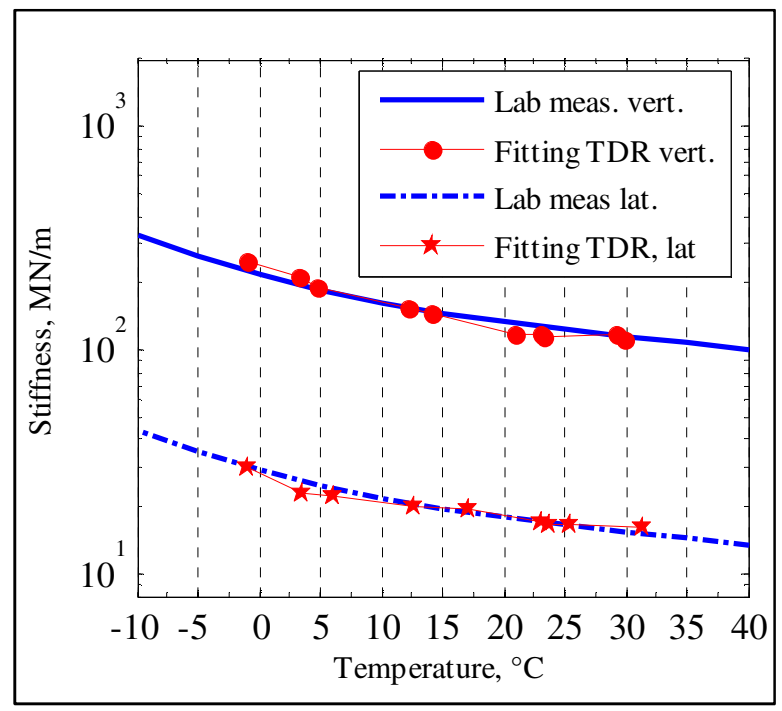

Figure 13. Railpad stiffness: measurements in the laboratory are compared with results predicted from fitting track models to measured TDR of Figure 7.

\section{Temperature effect on rolling noise, predictions and measurements}

\subsection{Field measurements and predictions from measured TDR}

In order to verify the effect on noise, a series of measurements was performed to record train pass-by noise on a straight track in Fishbourne, Sussex (UK). The track at this site is fitted with the same type of railpads as tested in earlier sections. The noise was recorded at three different times of the year with a sound level meter located at $7.5 \mathrm{~m}$ from the track centreline and $1.2 \mathrm{~m}$ above the top of the rail. The railpad temperature was monitored by using a thermocouple inserted between the rail and the pad so that each recorded pass-by could be assigned a temperature. The train speed was obtained from analysis of the axle passages and varied between $90 \mathrm{~km} / \mathrm{h}$ and $115 \mathrm{~km} / \mathrm{h}$. The trains were all of the same type: four-car class 377 electric multiple units (Electrostar). These vehicles have $0.84 \mathrm{~m}$ diameter wheels with straight webs and wheel-mounted disc brakes.

To allow for possible variations between the different measurements, the rail roughness was measured a number of times during the period of the measurements. The wheel 
roughness of a train of the same type was also measured. Figure 14 shows the rail and wheel roughness spectra. The rail roughness was found to be consistent although showing higher levels at the shorter wavelengths for the later measurements, performed in February 2015. The wheel roughness spectrum reported in the figure is the average roughness level of all the wheels of a single train. The wheel roughness levels are lower than the rail roughness in all wavelength bands. The contribution of the wheel roughness to the overall noise is therefore small.

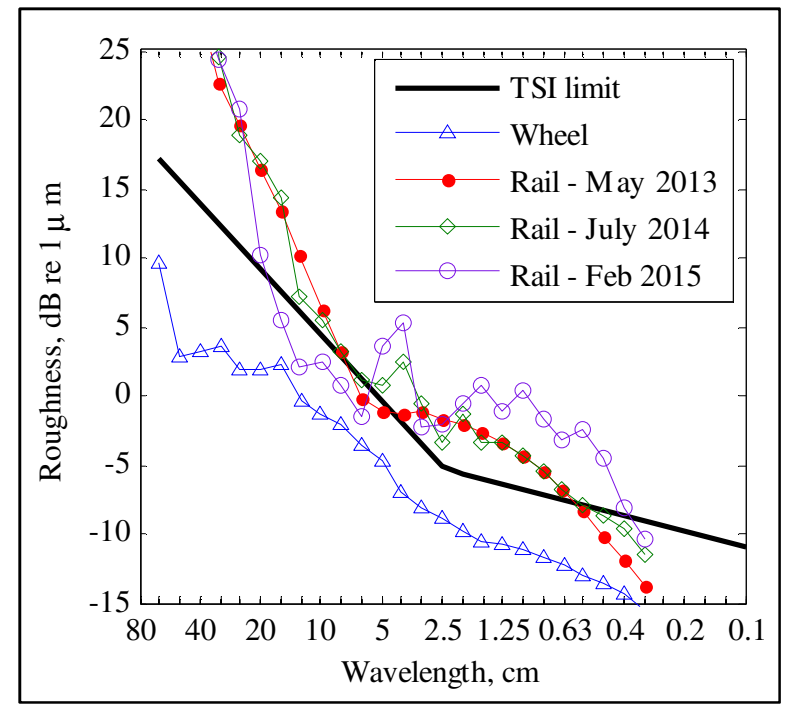

Figure 14. Wheel roughness and rail roughness spectra

Measured noise spectra are presented in Figure 15(a). In total 21 trains have been recorded on three different days between June 2013 and February 2015. These are shown as A-weighted spectra, and have a broad peak between 1 and $2 \mathrm{kHz}$. Because these results include variability due to both speed and temperature a clear trend with temperature cannot be deduced directly from this figure, but will be shown for overall noise below.

In parallel, rolling noise predictions have been obtained with a model based on TWINS 21. The same parameters as in Table 1 have been adopted for the track with the sleeper modelled as a flexible body. In this model the effect of temperature has been considered indirectly by using the track decay rate measured on the test track at various 
temperatures (Section 3). Pad stiffness and loss factor have been chosen according to the temperature (i.e. corresponding to the decay rates), however, when measured decay rates are used, the values used in the analytical model for the pad properties have only a marginal effect. The roughness adopted in the calculation is the one measured in February 2015 while a constant speed of $105 \mathrm{~km} / \mathrm{h}$ is assumed in the model. Calculated noise spectra are shown in Figure 15(b). In this case there is a clear trend of higher radiated noise with increasing temperature. Predicted noise spectra are affected by temperature between $500 \mathrm{~Hz}$ and $2 \mathrm{kHz}$ which is where the TDR has most effect on the rail response. To illustrate this Figure 16 shows the three components responsible for radiating noise: sleeper, rail and wheel. Track decay rates measured at $30{ }^{\circ} \mathrm{C}$ have been used as an example. The rail is dominant between $500 \mathrm{~Hz}$ and $2 \mathrm{kHz}$, exactly the range where temperature plays an important role.

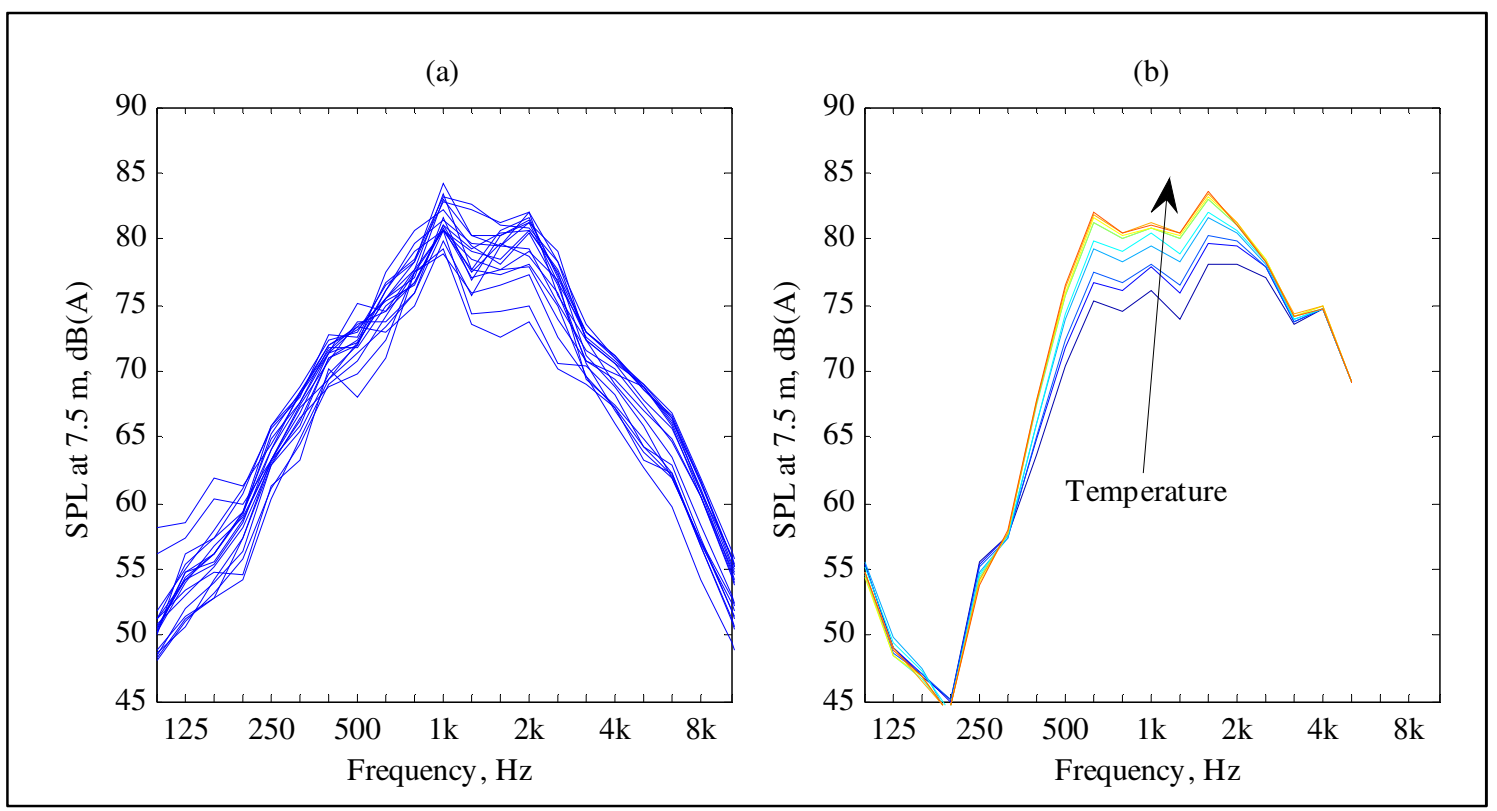

Figure 15. A-weighted sound pressure spectra at $7.5 \mathrm{~m}$ for (a) measured and (b) calculated passby. The measurement includes variability of both temperature and speed while the calculations are shown for different temperatures at a constant speed of $105 \mathrm{~km} / \mathrm{h}$. 


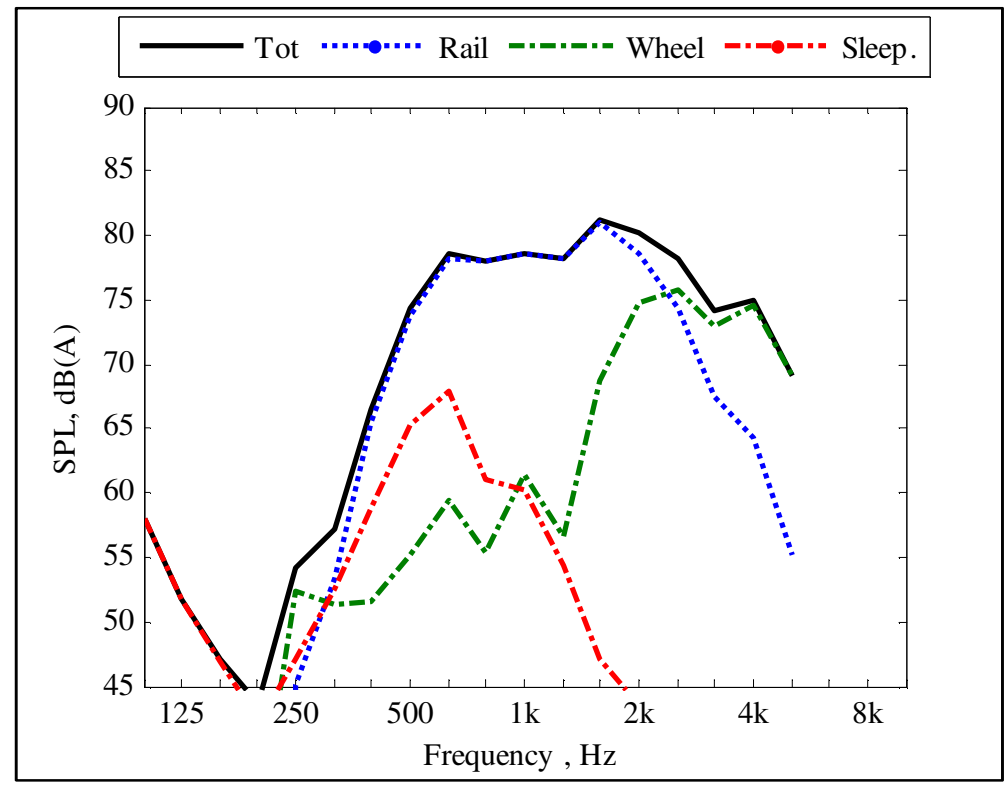

Figure 16. Predictions of components of noise spectra at $30^{\circ} \mathrm{C}$ for natural rubber pads.

To deduce the effect of temperature from the measured data, the noise spectra have been corrected for differences in roughness and the resulting overall pass-by noise level has then also been corrected for speed differences. Corrections for roughness, although small, allow a comparison between sets of data obtained on different days. To compensate for differences in speed the typical speed dependence of rolling noise is assumed ${ }^{1}$ :

$$
\Delta L_{p}=30 \log _{10}\left(V / V_{\text {ref }}\right)
$$

where $\Delta L_{p}$ is the change in sound level between speeds $V_{\text {ref }}$ and $V$. The overall noise level is shown in Figure 17 plotted against temperature for both model and measurement. The trend from the predictions agrees well on average with the trend from the measurements although, at a given temperature, the measurements have a variability of up to $2 \mathrm{~dB}$. In both the model and the measurements the noise is found to increase by about $3-4 \mathrm{~dB}(\mathrm{~A})$ between $0{ }^{\circ} \mathrm{C}$ and $35^{\circ} \mathrm{C}$. Both speed and roughness corrections are important to capture the trend with temperature from the measured data. The roughness correction makes the data measured on different days and at similar 
temperatures consistent, while the speed corrections decrease the measurement variability.

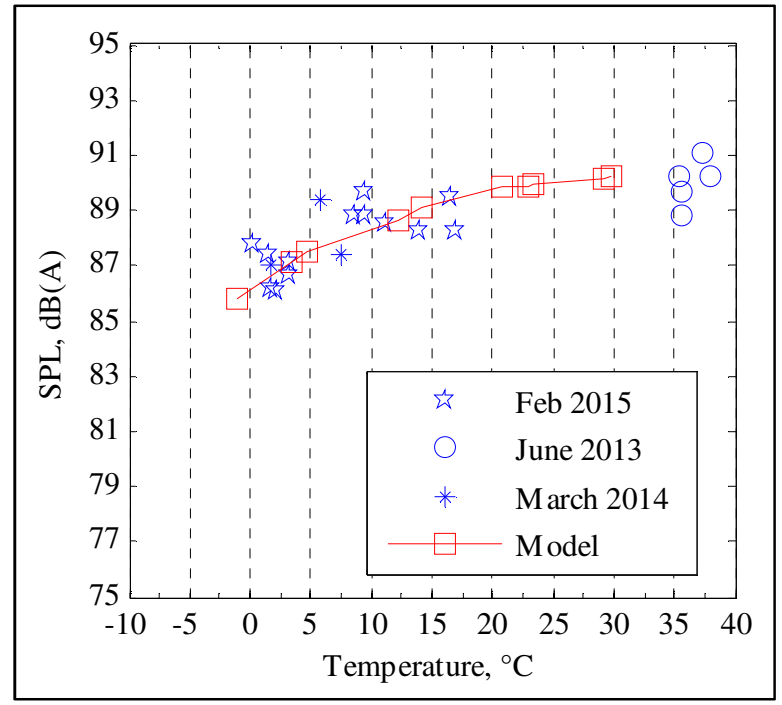

Figure 17. Dependence of overall pass-by noise on temperature. Measured noise is corrected for speed differences according to Eq. (11) and for roughness. Predicted noise is obtained from measured data rates.

\subsection{Predictions from laboratory measured data}

Following the same procedure, pass-by noise has been predicted using the results from the laboratory measurements for both railpads over the full temperature range. The vertical and lateral pad stiffness of the natural rubber pad is set as in Figure 13 (laboratory measurements lines); the stiffness for the cork-rubber railpads is found by rescaling the shear modulus trend (Figure 4(a)) with temperature to give a pad stiffness of $550 \mathrm{MN} / \mathrm{m}$ at $10^{\circ} \mathrm{C}$. This was again found by curve fitting measured decay rates; note that only one measurement is available for this railpad and the trend of the laboratory measured stiffness could not be checked over a wide range of temperatures. The lateral stiffness is obtained by rescaling the vertical one by the same factor found for natural rubber pad, which is about 7.5. The loss factor is varied with temperature according to the laboratory measurements as described in Section 2.4. 
Figure 18 shows the railpad stiffness adopted in the model for both railpads for both vertical and lateral directions.

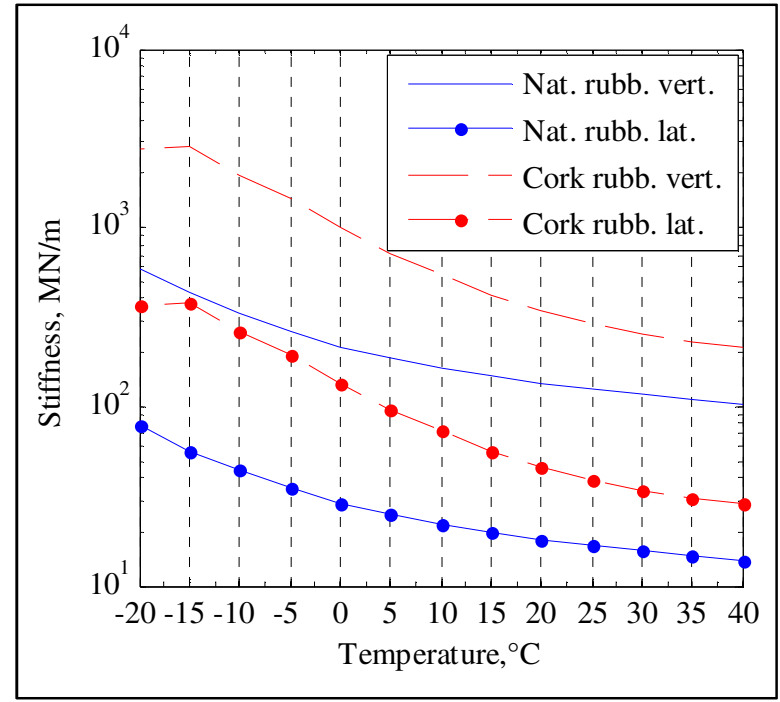

Figure 18. Vertical and lateral railpad stiffness at various temperatures as adopted in noise prediction model.

Predicted noise spectra are given in Figure 19. The results for the natural rubber pad agree with those obtained with the measured decay rates (Figure 16(b)) but here a wider temperature range is covered. The cork-rubber pads (Figure 19(b)) show similar behaviour but with some differences due to the greater stiffness of this pad. At low temperature the pad stiffness is expected to be $3000 \mathrm{MN} / \mathrm{m}$; as a consequence vibration is readily transmitted to the sleeper and the rail tends to radiate less noise. In fact the spectra at low temperatures show a dip in the frequency range dominated by the rail. With increasing temperature the coupling with the sleepers becomes less strong and the rail radiates more noise causing the overall level to increase. 


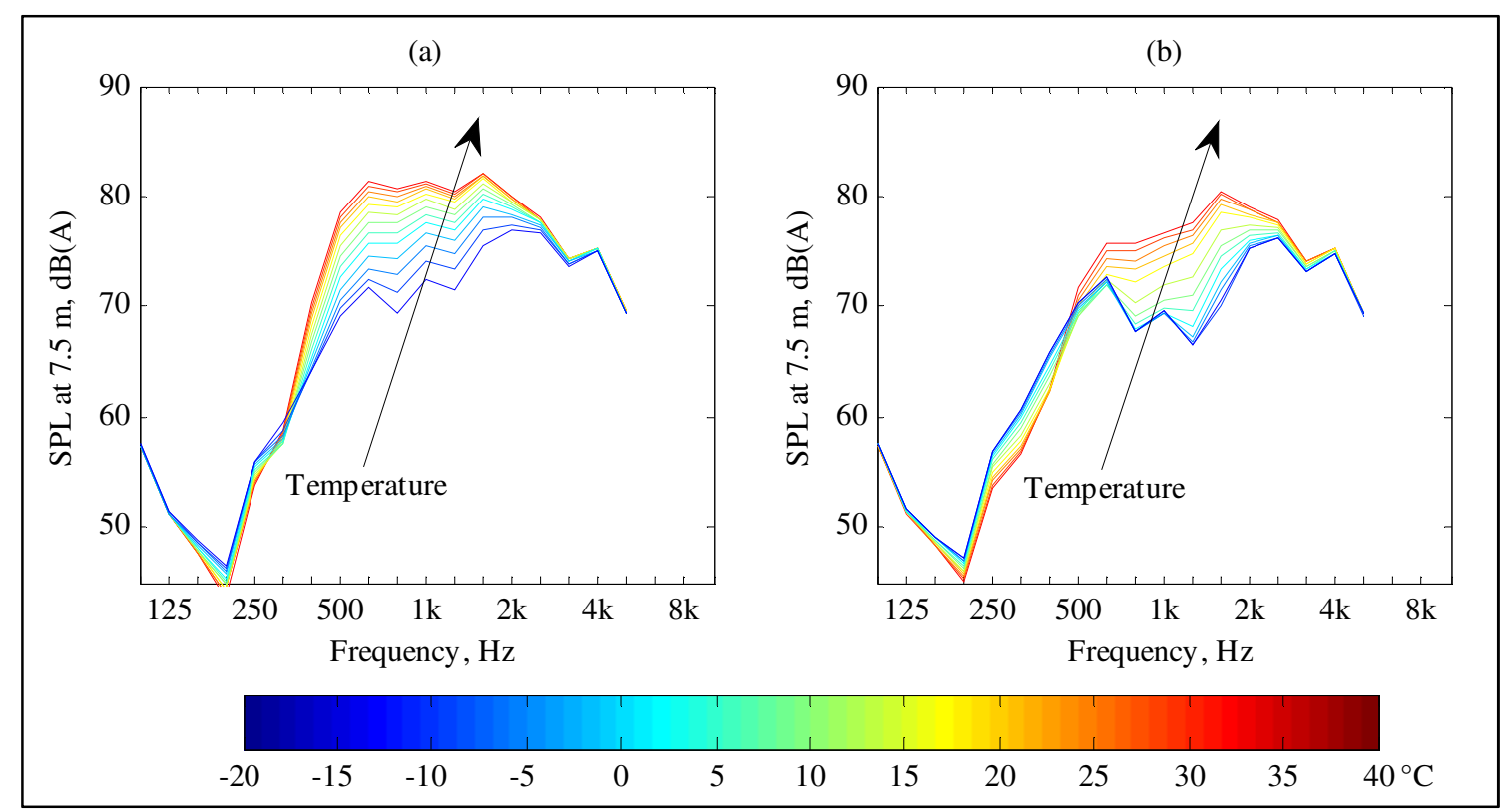

Figure 19. Predicted noise spectra based on laboratory stiffness measurements for (a) natural rubber and (b) cork rubber pads.

Similar conclusions can be drawn from the overall noise which is shown in Figure 20 for the three track components. For the natural rubber railpad (Figure 20(a)) the overall noise is mostly influenced by the rail and it increases by $6 \mathrm{~dB}(\mathrm{~A})$ for temperature from $20{ }^{\circ} \mathrm{C}$ to $40{ }^{\circ} \mathrm{C}$. Below $10^{\circ} \mathrm{C}$ the noise drops at a slower rate: the wheel component is more important for stiffer railpads and this is not predicted to change with temperature. The rail component alone is predicted to increase by $9 \mathrm{~dB}(\mathrm{~A})$.

For the stiffer cork-rubber railpads the overall noise is dominated by the wheel from - 20 ${ }^{\circ} \mathrm{C}$ up to $15{ }^{\circ} \mathrm{C}$. At very low temperatures, rail and sleeper components are comparable. Above $0{ }^{\circ} \mathrm{C}$ the railpad becomes softer and the overall noise starts increasing more significantly. In this case the total increase in noise over the temperature range analysed is approximately $4 \mathrm{~dB}(\mathrm{~A})$; however, this is again limited by the wheel component becoming more important at low temperature, the rail component alone being predicted to increase by almost $10 \mathrm{~dB}(\mathrm{~A})$. 


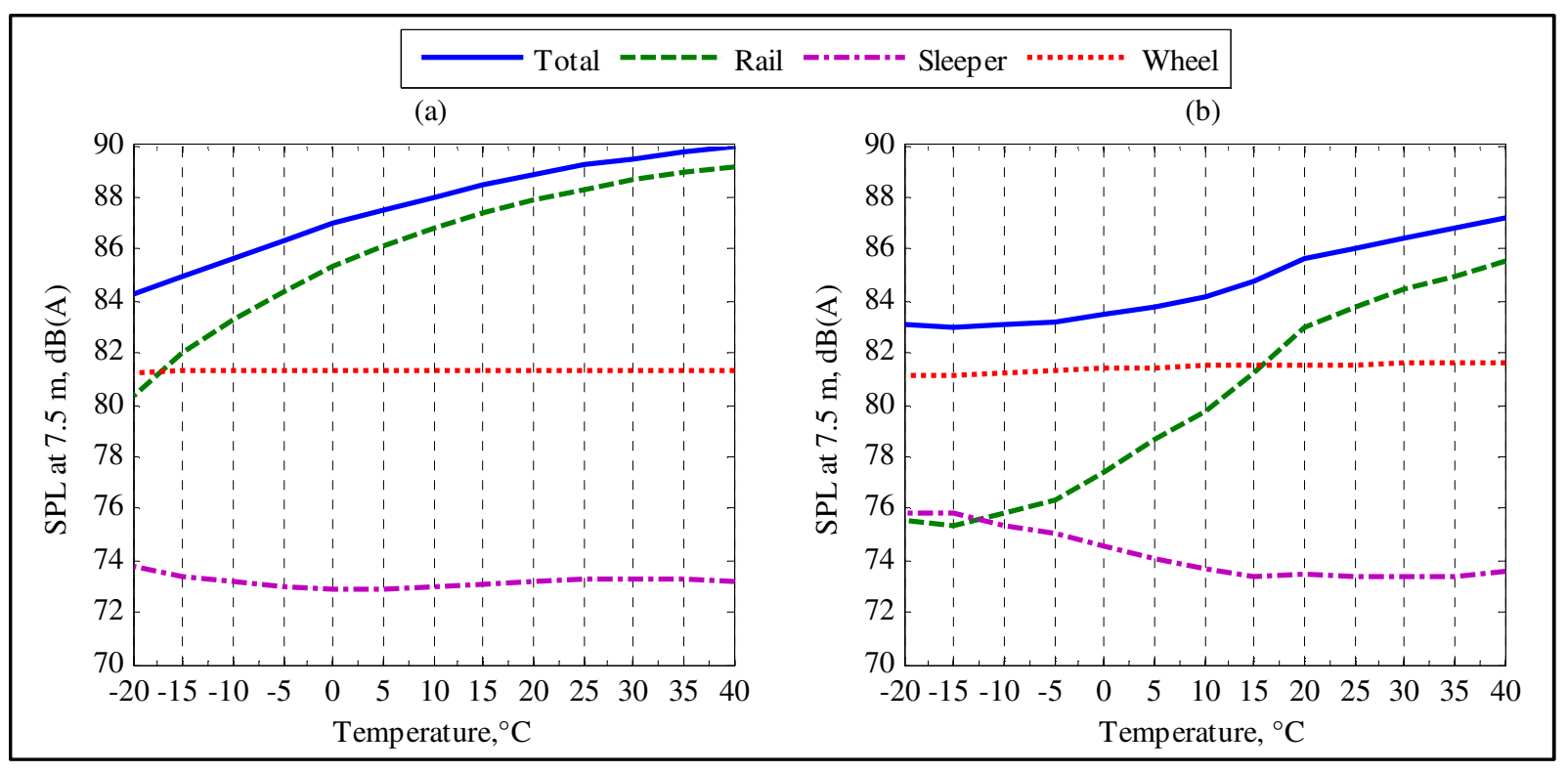

Figure 20. Overall sound pressure level predicted for different temperatures based on laboratory stiffness measurements. (a) Natural rubber railpad; (b) cork rubber railpad.

\section{$5 \quad$ Conclusions}

This paper has highlighted the effect that temperature can have on rolling noise. In the first place, measurements in a temperature-controlled environment were taken to determine the dependence of the railpad material properties on temperature. The shear modulus of the natural rubber used in the railpads tested here has been shown to increase by almost a factor of 6 when the temperature decreases from $40{ }^{\circ} \mathrm{C}$ to $-20{ }^{\circ} \mathrm{C}$ while for cork reinforced rubber it has increased by a more than a factor of 10 .

Measurements of track decay rates at different temperatures taken on a test track have been used to estimate the pad stiffness as a function of temperature. These have been obtained by curve fitting the measured data using the decay rates from an analytical model. A good agreement has been found between the temperature dependence of the pad stiffness estimated from the laboratory measurements and from curve fitting the decay rates. 
A set of field measurements of train pass-by noise for a track fitted with natural rubber pads has been obtained over a wide range of temperatures while registering the railpad temperature. The overall noise was found to increase by about $3-4 \mathrm{~dB}(\mathrm{~A})$ between $0{ }^{\circ} \mathrm{C}$ and $35{ }^{\circ} \mathrm{C}$. Rolling noise predictions obtained using track decay rates measured on the test track at different temperatures showed a trend similar to the field measurements, also increasing by about $4 \mathrm{~dB}$ in the same temperature range.

Predictions have also been shown over a wider temperature range $\left(-20^{\circ} \mathrm{C}\right.$ to $\left.40{ }^{\circ} \mathrm{C}\right)$ by adopting the stiffness measured in the laboratory for two types of railpad. In this case the natural rubber pads give an increase in overall noise of $6 \mathrm{~dB}(\mathrm{~A})$ while the stiffer cork-reinforced railpads $4 \mathrm{~dB}(\mathrm{~A})$. In the second case especially, the increase in noise is limited by the wheel contribution. For both pads the contribution from the rail only is expected to be substantially influenced by the temperature as it has been predicted to increase by between 8 and $10 \mathrm{~dB}(\mathrm{~A})$.

Further analysis considering different railpad materials and track designs would be required to confirm the outcomes presented here. Nonetheless this first assessment is sufficient to show that there is a need for careful control of temperature when measuring track decay rates. This should be considered for inclusion in the standard as measurement performed at one single temperature, perhaps taken overnight, could not be representative of the same track on a warmer day.

\section{Acknowledgements}

Most of the work described has been supported by the EPSRC under the programme grant EP/H044949/1, 'Railway Track for the 21st Century'. All data published in this paper are openly available from the University of Southampton repository at http://dx.doi.org/10.5258/SOTON/381106. 


\section{References}

1. Thompson D. Railway Noise and Vibration: Mechanisms, Modelling and Means of Control. Elsevier Science, 2009.

2. Esveld C. Modern railway track. MRT-Productions, 2001.

3. Vincent N, Bouvet P, Thompson DJ and Gautier PE. Theoretical optimization of track components to reduce rolling noise. Journal of Sound and Vibration. 1996; 193: 161-71.

4. EN 13146-9:2009+A1:2011 Railway applications. Track. Test methods for fastening systems. Determination of stiffness.

5. ISO 10846-2:2008. Acoustics and vibration -- Laboratory measurement of vibro-acoustic transfer properties of resilient elements -- Part 2: Direct method for determination of the dynamic stiffness of resilient supports for translatory motion.

6. ISO 10846-3:2002. Acoustics and vibration -- Laboratory measurement of vibro-acoustic transfer properties of resilient elements -- Part 3: Indirect method for determination of the dynamic stiffness of resilient supports for translatory motion.

7. Thompson DJ, van Vliet WJ and Verheij JW. Developments of the indirect method for measuring the high frequency dynamic stiffness of resilient elements. Journal of Sound and Vibration. 1998; 213: 169-88.

8. Thompson DJ and Verheij JW. The dynamic behaviour of rail fasteners at high frequencies. Applied Acoustics. 1997; 52: 1-17.

9. Fenander A. Frequency dependent stiffness and damping of railpads. Proceedings of the Institution of Mechanical Engineers, Part F: Journal of Rail and Rapid Transit. 1997; 211: 51-62.

10. Maes J, Sol H and Guillaume P. Measurements of the dynamic railpad properties. Journal of Sound and Vibration. 2006; 293: 557-65.

11. Brazel C and Rosen S. Fundamental Principles of Polymeric Materials. Wiley, 2012.

12. Nashif A, Jones D and Henderson J. Vibration damping. Wiley, 1985.

13. Mead D. Passive Vibration Control. Wiley, 1999.

14. Ahmad N, Thompson DJ, Jones CJC and Muhr AH. Predicting the effect of temperature on the performance of elastomer-based rail damping devices. Journal of Sound and Vibration. 2009; 322: 674-89.

15. Broadbent R, Thompson DJ and Jones CJC. Evaluation of the effects of temperature on railpad properties, rail decay rates and noise radiation. In: Pawelczyk $\mathrm{M}$ and Bismor D, (eds.). Proceedings of the 16th International Congress on Sound and Vibration: Recent Developments in Acoustics, Noise and Vibration (ICSV16). International Insitute of Acoustics and Vibration, 2009.

16. Maes J. The reductions of vibrations in railway track through the application of non-linear modelling. Vrije Universiteit Brussel, 2006.

17. Ahmad N. A methodology for developing high damping materials with application to noise reduction of railway track. University of Southampton, 2009.

18. Schwarzl FR and Struik LCE. Analysis of relaxation measurements. Advances in Molecular Relaxation Processes. 1968; 1: 201-55.

19. Ferry JD. Viscoelastic properties of polymers. New York: John Wiley \& Sons, 1970.

20. EN 15461:2008. Railway applications - Noise emissions, Characterization of the dynamic properties of track sections for pass by noise measurements. 
21. Thompson DJ, Hemsworth B and Vincent N. Experimental validation of the TWINS prediction program for rolling noise, Part 1: description of the model and method. Journal of Sound and Vibration. 1996; 193: 123-35. 